\title{
Ludic Activity of Writing Using Wattpad as Digital Fiction Engagement and Meaning Experiences
}

\author{
Sri Kusumo Habsari ${ }^{1}$, Diah Kristina ${ }^{2}$, Fitria Akhmerti Primasita ${ }^{3}$, Yusuf Kurniawan ${ }^{4}$, M. \\ Taufiq Al Makmun ${ }^{5}$, Karunia Purna Kusciati ${ }^{6}$ \\ \{skhabsari@staff.uns.ac.id \} \\ English Department, Faculty of Humanities, Universitas Sebelas Maret
}

\begin{abstract}
The capability of Wattpad to provide a space for writers to publish their works, either original or fan-based stories and multiplatform entertainment for all users and its popularity demonstrate the evolution of authorship. This study attempts to explore university students' engagement with Wattpad as a digital fiction platform to understand their writing and reading experiences and their ludic activity as a strategy to develop their meaningful existence in their virtual and social world. Data are collected through distributing Google form survey on social media. Questions asked to respondents willing to participate on this survey are both multiple choices and open questions that are designed to identify the participants' digital activity across platforms and their ludic experiences in using Wattpad as both consumer and prosumer. Finding shows that Wattpad has revolutionized the notion of writing fiction through participatory culture offered to users to engage with this platform as a medium to express their creative imagination. Most respondents are not dedicated writers and they publish their story when they have mood to write. Writing is considered as just a ludic activity, so do narratives they develop. However, support and comments accepted on the margin encourage them to continue writing. Thus, Wattpad for writers is a part of their identity expression to be recognized socially although it is mediated through digital platform.
\end{abstract}

Keywords: Ludic experiences, Wattpad, Participatory Culture, Authorship Evolution

\section{Introduction}

Beginning from the Web 2.0 technology with the emergence of Wikipedia, Blogger, YouTube, or Facebook application, internet users have been shifted into empowered hypertext creators. The enculturation of Web and everyday activities has tremendously changed the nature of social customs and communicative practices. The tradition of communication has shifted from one-to-many communication into the paradigm of many-to-many communication. Web 2.0 becomes new types of application, new social formations, and new business models as well [1]. Internet becomes a social space, which later on leads into the birth of social media applications.

The key feature of internet as a social space is in its interactivity and participatory [2]. Users have been provided a medium to both download and upload any content. With the liberation from tight technical restraints, users have undergone a transformation into authors since they are free to publish any content and they can focus into contents without ever thinking the technical restraints of the language of the program [3]. Although the internet has provided online interaction, there are still some restrictions because not all people can post any content to the 
websites or blogs. Some blogs certainly provide a space to post a comment, however, the interaction is still limited.

It has been general perception that the practice of using social media platforms is rarely a single dedicated act. Users generally play across varying media platforms. They read, watch, play and back to read simultaneously. They do not attend at a single point in time and space to focus, like their predecessors. New media technologies as the backbone of the development of social media platforms allow the emergence of and convergence of sites of platforms as new spatial experiences through interactive cultural experiences

Although the social space of social networking platforms is based on virtual environment mediated by specific platform, users are still expected to behave in certain values and practices. Social norms are bound to the platform restricting the practice of participation and collaboration since the context of the creation is designed to connect people sharing similar interests. LinkedIn, for example focuses for professional networking. Twitter limits users only to post 140 characters until 2017. Instagram in the beginning only focuses on sharing photos and videos. This makes online interactions become complex and problematic at the same time. Facebook is designed to connect a circle of friends having common bonds. Some platforms are created for dating, although it is not about an actual dating. Myspace is used by people sharing similar interests on music, especially bands and musicians. Egocentric collections seem to be the emphasis on the social networking platform interaction [4] People only join and participate when they are interested. They are bound only with the online communities sharing similar interest and could neglect other values and practices.

Many platforms are designed to provide a space for users to upload their narrative creation. In its development, the design of the platforms is structured which could contain the shattered narratives from many media to maximize users' social engagement and extensive immersion to only one site. Users can play out many contents in a single session and single place, such as reading fiction and social networking or playing game while dating.

There are many platforms dedicated for users to read and share stories, such as Wattpad, Penned, Shorti, Mirakee, TaleHunt, Movellas, Medium, Pocket Writers, Tablo, Hooked, Penana, Sweek, Inkvite, Twine, Inform 7 and many others. All of these applications mentioned share similar interface which allows users to follow, share to other platforms, leave comments, personalized chat, and connect with others, both community of writers or readers. However, every platform provides its uniqueness, such as in Penana which allows collaborative writing, Mirakee which is more like blogging of writing or discovering quotes, stories or poems, or Fanfiction.net which focuses only for archiving fanfiction. While Twine and Inform 7 are more dedicated to provide writers to design interactive fiction, through combining hypertext narrative and html and bring the readers the transgression and challenge of the text.

Among those, Wattpad is one of the most popular platforms. Founded in 2006 by two Canadians, Allen Lau, and Ivan Yues, this platform provides a space for both writers to publish their work and to connect with others. Thus, this platform is a combination between publishing works and social networks. Wattpad also provides numerous opportunities for writers to publish their aspiring works or just reinterpret and reinvent narration they read from other platforms, such as from movies, TV series, videogames, classical fiction and many others. The great value of the platform is the capability of the writers to upload only two chapters at a time and to invite comments and advice of each chapter before uploading the next two chapters.

The readers can award stars to show their support and to follow the users' profiles. They can join thematic clubs also to participate in a discussion on a particular genre. Wattpad also offers the users to buy some coins to read particular paid stories, the cost is ranged from five to fifty-five thousand rupiah in change of nine to two hundred and sixty coins. Aside from coin 
menu, the platform also offers an upgrade to premium account with some benefits like free from advertisements, bonus coins, unlimited offline stories, and many more.

The popularity of Wattpad has encouraged many researchers to explore the online writing and reading platform. Scholars are attracted to the culture of participation such as social collaboration and production [5]; the dynamic relationship between author and reader which is more proactive and interactive [6]; the evolution of authorship of which authors can become networked micro-celebrities [7]; social authorship in which author does not any intention of commercial purposes [8]; and the dynamic network of reader and writer to increase text circulation [8] [9]. It still opens possibility to many discussions.

The Wattpad revolution to break boundaries between publishers, writers and readers, as it has been mentioned, raises up the question of the emergence of the ludic activities of the users in their engagement with the narratives of the story published in Wattpad. The term ludic is derived from game studies which means 'playful in an aimless way'. Meanwhile, games provide gamers with narratives to set up the goal of the games. The intersection between ludic and narrative element produces the term ludonarrative or the interaction between gamers and narrative of the game which could be disharmonious.

Discussion on ludonarrative is mostly on the polarization in the narrative of the games whether the mechanics and the narrative of the games are harmonious or dissonant and resonant or cohesive in the immersive gameplay experience. Some research on video games have found out that the mechanics of the game do not unite with the narrative, such as in the game Bioshock and Call of Duty 4: Modern Warfare [10] [11]. Some researchers suggest how to create synergy between narrative and mechanics [12].

Wattpad is not considered as a game, since it does not provide enough elements of gameplay. The objective which should be achieved by the users is also not similar with the elements of gamification of which every gamer struggle to play and win. Games provide users game mechanics to confront players to achieve certain goal. Meanwhile, the foundations of Wattpad are the combination of technology and story which requires the Wattpad users to take action to interact with the system provided by the platform designers by expressing their emotional responses to the stories. The users also should make choices in the participatory culture of the story selected to read with the unpredicted outcomes. With only two chapters uploaded in every section, the users could be driven to express their concern to the narrative of the next chapters. This phenomenon raises a question of ludonarrative meaning making of the users engagement with the narratives.

In terms of narrativity, the computing technology of Wattpad requires the writers to adapt the narrative of the network communication technologies. The authority of the writers as 'the normative model privilege' is negated because of the integration between the production and reception activities. Although the readers could not modify the work, and it seems still unusual, the participatory culture of the platform allows the dynamic and ongoing process of the writing which could navigate to different direction of the creation of character development, setting and description. The shifting suggests the notion of network narratives which incorporate the participation and communication practices.

Thus, this study attempts to argue that the easiness and freedom to publish in Wattpad has produced different meaning experiences of writing and reading tradition. Writers consider writing fiction and publishing as just ludic activity since writing fiction is not their main intention in life. Narrative structure which is the foundation of the story of which they should maintain is neglected. Although the narrative structure is fragmented and the dedication to finish writing stories fails to carry out, it is still acceptable, and they gain comments and supports from 
their readers. Thus, their engagement to narrative of chapters of stories is just for playful activity.

\section{Research Methods}

The emergence of digital fiction has attracted many scholars to study a web-based or appbased fiction. Digital fiction is different from printed version or digital version of print novel. It is born digital fiction and raises issues of both aesthetic and structural form and meaning. Hyperlink, both still and moving images, games and sound are possibly available elements readers interact during their engagement with digital fiction. Readers can control the narrative just by selecting hyperlinks or exercising character's journey in the story world. The border between writers and readers of print version tradition has been collapsed through the availability of margins of comment section for interaction between readers and/or writers. Such new elements encourage researchers to develop certain method to analyze born digital fiction.

Many researchers are attracted to study what are posted in Wattpad. With 100 million stories uploaded in 2015 [13] and the huge number of reads/votes/comments, big data analysis using algorithm generated list is the method mostly used to study such phenomenon [14]. Some researchers apply netnographic approach to capture the social environment and dynamic relationship of Wattpad [15]. Others have a goal to study reader's response to narratives on the margin of Wattpad by comparing the domain of text as a form and comments as effects employing both quantitative and qualitative analysis [16] [17] and multimodal experience of readers in their interaction with texts in a platform through conducting survey analysis or Focus Group Discussion [18]. Despite various methods which can be applied to study the evolution of the tradition of writing fiction, most researchers agree that in terms of aesthetic analysis, traditional convention of analyzing fiction should be redefined to meet the unique characteristic of digital fiction.

The aim of the research is to explore and understand the university students' engagement and meaning experiences in using the Wattpad platform. The research process involves designed questions and procedures to gain data through employing simultaneous data collection and analysis. By comparing the data with emerging categories, its goal is to achieve maximum generalization from the similarities and differences in information. Some suggest to study a

In the interest to reach out participants wider and easier, the participants of the study are recruited with Google Forms, a web-based survey tool provided by Google Inc. Most of the questionnaires are multiple choices that are structured to identify the participants' digital activity across platforms. The rests of it are open-ended questions that require short answers to obtain information on their digital literacy: their skills to generate digital content and share across different platforms which need skills of distribution, remixing and participation. The researchers also simultaneously share the URL of the Google Forms to some online platforms such as WhatsApp Groups and Twitter to gain wider participants. After gathering some responses, the researchers filter the respondents into some criteria in relation to model of consumption as active readers, creative production and distribution. 


\section{Results and Discussion}

The researchers posted and shared the URL of the Google Forms (bit.ly/LudonarrativeWattpad) to some WhatsApp Groups and Twitter bases like @UNSfess_ and @ collegemenfess which have such big number of followers. The data was collected for a week, from the 7th to the 14th of August 2020. The survey is divided into two categories for Wattpad users considered themselves as readers or writers. The questions asked to respondents are about the kind of activities they have undertaken using Wattpad. It surveys their active engagement as both readers and writers and their participation and interaction with/ between writers and readers. A range of questions of the type of activities are asked to explore whether Wattpad as digital fiction platform encourage them to participate in narrative development. In total, the online survey has successfully collected 196 responses from many cities in Indonesia. Among those, 83 respondents categorize themselves as writers and 155 users considers themselves as active readers.

The respondents of the survey show the disparity in their age. Some of them are teenagers and the dominant age responding to the survey is 18-22 years old. In term of sex, 185 female respondents answer the survey questions. Most of them have also actively used Wattpad more than 2 years. Even, 42 respondents have used Wattpad for more than 6 years. Aside from 196 respondents answering the survey, only 6 respondents identify themselves as a purely writer. 77 respondents answer both. Such answers raise up the issue of the shift of consumption notion from literacy involving elaborated textual system of reading and writing engagement into broader ecology of literate system through consumer-led creativity across various media platforms.

Reading and writing on Wattpad require new skills to engage with digital technologies. It also forces to master strategies and dispositions to adapt new communication landscape in which information rapidly changes. The ability to access, analyse and evaluate texts encompasses dynamic processes of understanding and evaluating contested aesthetic, economic, ideological and political contents that lead into content creation. Both reader and writer become proactive and interactive to gain popularity and pay attention specific trend, domains, and times which lead to the emergence of influencers. Such evolution which breaks down the tradition of writing fiction need to put into a different context in understanding the meaning experiences of writing digital fiction.

In attempt to understand the meaning experiences of Wattpad users, the survey is designed by categorizing the participants into two different types of readers: active and passive. Apart of 196 responding to the survey, only 77 respondents consider themselves as active readers. The term 'active' refers to the activities of commenting, voting, sharing, following writers' account, screenshotting and quoting. The survey design considers the old fashion of reading printed text which does not provide medium to express their cognition to texts. However, it is general opinion that readers are not passive in text reception. The number of readers' community with members actively shares their opinion, perception or perspective to texts show that readers are not passive dupe shallowing narratives and all fiction elements as written by authors.

Meanwhile, Wattpad as digital fiction platform recognizes the need of users to share their perception and opinion although it is only in the act of sharing or highlighting as well as the extension beyond virtual environment such as writing, distributing, or criticizing. Readers could participate to the practice of social reading to share their reading experiences or engaging in discussions in the margins provided. The easiness for the users to write their comments on the margin provided is one of the reasons for the users to participate to the practice of social reading through giving comments (78 respondents), voting (66 respondents), sharing (27 respondents), 
or following the writer's account ( 2 respondents). When they make comments, they ask to continue the story as soon as possible (43 respondents). 22 respondents suggest correcting the grammar, word choices, dictions, spelling, or format. Among those, only 7 respondents suggest some ideas for the next narrative.

Mostly express their perception to the characters, scenes, conversation, or the plot of the story. Such finding suggests the dynamic interaction between reader and writer. Although only 7 respondents throw out their idea for the next chapters, it brings about the notion of how readers become proactive and break down the separation between reader and writer. With direct communication which allows all parties to coexist in the margin of comments, author can gain more insight or get any feedback for developing narratives while readers can express their demand and concern in which such collaboration can support to gain popularity. Writers can become micro-celebrities and readers happen to be influencers.

The issue of authorship is also fascinating to discuss although the notion has been transformed from author as solitary genius individual into collaborative society. The dependence of authors to publishing industry which could make the fame of the author is considered as outdated opinion [19]. Disparity of income between popular and well-known writers is high to compare with low-ranking authors. The digital technology evolution has changed the social context of publishing into more democratic and open. Aspirations are the key for both parties which are shared on various social media platforms.

The goals of writing are no longer focused on gaining income but are directed into just to gain recognition. Support and sharing become the key actions in the tradition of writing on digital platforms. Some writers tend to choose popular or well-recognized topics. The author's intention which is the foundation of fiction structure is missing. Writers rarely consider messages of stories they create. Their focus is mostly on characters' development inspired from their fandom to celebrities or any popular media products. Originality is also being questioned. Fantasy and imagination are their foundation of writing stories. They could write anything without considering morality since no publisher as the gatekeeper of morality mediates their publishing fiction.

Another issue coming up from the survey is their dedication of finishing their writing fiction. The possibility of writing short fiction and limited chapters of every publication encourage many users to write their fiction. Most of respondents acknowledge their unoriginal works since they develop their stories based on popular topics of their circle, such as fandom expressions to celebrities or popular film and fiction. Fantasy and imagination are the key points to develop their stories. They neglect narrative structure as the foundation of story development. They also write based on their mood.

Thus, writing fiction is a ludic activity because they only play with writing texts and the intention is not to send messages, rather than to achieve the goal of gaining attention from public. Since narrative is built with ludic activity, disharmonious ludonarrative is often found on their stories published in Wattpad.

\section{Conclusion}

This paper attempts to argue that Wattpad has revolutionized the tradition of writing fiction from dedicated into ludic activity. Participatory culture as the foundation of Wattpad as a writing and reading fiction platform has opened up possibilities of users to be both readers and writers. Since users are free to publish their stories and/or give comments to stories they read, they 
consider writing and to publish their writing for their fun activity. It raises an issue of authorship notion. When they write and share their stories, they just express their fantasy and imagination of the most popular topics discussed in their circle. Having mood to write is their reason of writing and publishing in Wattpad.

Thus, they do not have burden to continue writing until the ending of the stories. Their meaning experiences of using Wattpad is just like playing with writing texts and they neglect the narrative structure which is the foundation of writing fiction. The intention of using Wattpad which is to provide a medium for writers to share their fiction and to free them from publishers which could hinder their publication intention is driven away into a playful activity with an intention ta gain recognition from their circle. Although the narrative structure formation is neglected, focusing only on characters' development which could be inconsistent in the next chapter published, readers rarely problematize and criticize the disharmonious or fragmented narrative structure.

Readers' focus is also directed to characters' development since most characters are developed from their fandom to celebrities, film, fiction or any other media products. Since the reading intention and narrative of stories do not meet, some fictions published in Wattpad raises issue of disharmonious ludonarrative from both writers and readers engagement to stories.

\section{References}

[1] V. Eisenlauer, A Critical Hypertext Analysis of Social Media, London: Bloomsburry, 2013.

[2] H. Jenkins, Convergence Culture: Where Old and New Media Collide, New York: New York University Press, 2006.

[3] H. Boyd, "Social media: a phenomenon to be analyzed.," Social Media + Society, vol. 1, no. 1, pp. $1-2,2015$.

[4] H. Boyd, "Why youth heart social network sites: the role of networked publics in teenage social life," in Youth, Identity, and Digital Media, Cambridge, MIT Press, 2008, pp. 119-142.

[5] Y. Benkler, The Wealth of Networks: How Social Production Transform Market and Freedom, New Haven: Yale, 2006.

[6] P. R. Murray, "The digital publishing communications circuit," Book 2.0, vol. 3, no. 1, pp. 3-23, 2013.

[7] A. Phillips, Turning the Page; The Evolution of the Book, London: Routledge, 2014.

[8] M. Ezell, Social Authorship and the Advent of Print., Baltimore: The John Hopkins University Press, 2003.

[9] J. C. Carriere and U. Eco, This is Not the End of the Book, London: Harvill Secker, 2011.

[10] C. Hocking, "Ludonarrative dissonance in Bioshock," $7 \quad 10$ 2007. [Online]. Available: https://clicknothing.typepad.com/click_nothing/2007/10/ludonarrative-d.html. [Accessed 2804 2020].

[11] T. Bissel, Extra Lives: A Phenomenon to be Analyzed, New York: Patheon Books, 2015.

[12] B. Abraham, "Gone home: jump scares and ludonarrative harmony," 178 2013. [Online]. Available: http://iam.benabraham.net/2013/08/gone-home-jump-scares-and-ludonarative-harmony/. [Accessed 28 April 2020].

[13] M. Meeker, "Internet trends 2015: code conference," [Online]. Available: https://www.slideshare.net/kleinerperkins/internet-trends-v1. [Accessed 28 July 2015].

[14] E. Bozgad, "Bias in algorithmic filtering and personalization," Ethics and Information Technology, vol. 15 , no. 3, pp. 209-227, 2013.

[15] M. R. Bold, "The return of the social author: Negotiating authority and influence on Wattpad," Convergence: The International Journal of Research into New Media Technologies, pp. 1-20, 2016.

[16] S. Rebora and F. Pianzola, "A New Research Programme for Reading Research: Analysing Comments in the Margins on Wattpad," DigitCult | Scientific Journal on Digital Cultures, vol. 3, no. 2, pp. 19-36, 2018. 
[17] F. Pianzola, S. Rebora and G. Lauer, "Wattpad as a resource for literary studies.," Plos One, vol. 15, no. 1 , pp. 1-46, 2020.

[18] D. J. A. J. Contreras, H. G. N. Gonzaga, B. M. Trovela and A. C. G. Kagaoan, "The "Wattyfever: Construct of Wattpad readers on Wattpad's role in Their Lives," LPU Laguna Journal of Arts and Sciences Communication Research, vol. 2, no. 1, pp. 308-327, 2015.

[19] J. Feather, "Copyright and the creation of literary property," in A Companion to the History of the Book, Oxfords, Blackwell, 2007, pp. 520-530. 